\title{
Knowing qualia: reloading the displaced perception model
}

\author{
Roberto Horácio de Sá Pereira (10 ${ }^{1 凶}$
}

How does one know the phenomenal character of one's own experience? I aim to present and defend a new view of the epistemology of qualia that addresses this issue. My view results from a reworking of Dretske's displaced perception model. The guiding line is the key Wittgensteinian insight of his Private Language Argument, namely the claim that no inner perception of qualia can justify our corresponding qualia-beliefs. My reworking of the original model starts with the rejection of Dretske's representationalism, as well as any other metaphysical views about the ultimate nature of qualia. The reworking of the displaced perception model I am proposing is supposed to be compatible with any available metaphysical view on qualia. The second step consists of rejecting the epistemological misgivings of the original model, namely the view that knowing qualia requires "connecting beliefs" along with "meta-representations." Yet, Dretske's crucial mistake has been to force knowledge of qualia into the "belief-box." As a matter of fact, there is only one belief involved in introspecting qualia, namely the qualia-belief itself. The third final step is this. Assuming the key Wittgensteinian insight, I argue that introspection of qualia is a process that is both epistemically reliable and automatic. It is reliable because it dispenses with justification of any beliefs whatsoever. Moreover, it is automatic because it also dispenses with reflexive connecting beliefs. For example, it takes nonconceptual awareness of the color blue as an input and automatically yields the belief that phenomenal blue is the conscious character of my experience of the sky as an output just by employing the concept BLUE.

\footnotetext{
${ }^{1}$ Department of Philosophy, Federal University of Rio de Janeiro/UFRJ, Rio de Janeiro, Brazil. ${ }^{凶}$ email: Robertohsp@gmail.com
} 


\section{Introduction}

veryone agrees that we are directly and a priori aware of the phenomenal character of our experiences (perceptions, emotions and bodily sensations) in the same way that we know directly and a priori our basic emotions, sensations, and contemporaneous cogito-like thoughts (e.g., I know that I am thinking now that water is $\mathrm{H}_{2} \mathrm{O}$ ). Yet, while the traditional inner sense model accounts for such awareness by adverting to some putative inner perception (some internal monitoring), ${ }^{1}$ by taking qualia as objects standing before the mind, Dretske proposed quite an interesting alternative model, which he called "displaced perception" (secondary perception). ${ }^{2}$

At first pass, the displaced model seems to offer obvious attractions. For a start, there is every reason to suppose that we are not acquainted with the phenomenal character of experience (say, phenomenal red) in the same way that we are acquainted with, say, the red color of a ripe tomato outside of our experiencing mind. Second, knowledge of phenomenal character is not "objectual," but rather a propositional (fact-knowledge): I do not know phenomenal blue as something before or inside my mind. Rather, I know the fact that phenomenal blue is the conscious character of my visual experience of the sky. Third, given that there is no inner perception of phenomenal red, we can only "perceive" the phenomenal character of our perceptual experience in a metaphorically "displaced" way, namely by perceiving something else outside the experiencing mind. Thus, for example, I can only "perceive" the phenomenal blueness of my visual experience of the sky via perceiving that blue is the color of the sky.

However, the displaced perception model faces severe criticism. Yet, I still believe the key insight behind the model is correct for the two reasons that I have mentioned above, regardless of your favorite metaphysics concerning the ultimate nature of the phenomenal character of experience. That said, this paper is an attempt to rework the displaced model of introspection of the phenomenal character of experience in a way that frees it from representationalism and all epistemological misgivings. The guiding line is the key Wittgensteinian insight of his Private Language Argument, namely the claim that no inner perception of qualia can justify our corresponding qualia-beliefs.

My reworking of the original model starts with the rejection of Dretske's representationalism, as well as any other metaphysical views about the ultimate nature of qualia. The reworking of the displaced perception model I am proposing is supposed to be compatible with any available metaphysical view on qualia; e.g., representationalism or qualia realism. ${ }^{3}$ Second, I reject the epistemological misgivings of the original model, namely the view that knowing qualia requires "connecting beliefs" along with "meta-representations." Nonetheless, Dretske's crucial mistake has been to force knowledge of qualia into the "belief-box." As a matter of fact, there is only one belief involved in introspection of qualia, namely the qualia-belief itself.

Assuming that no possible inner perception of qualia could justify our corresponding qualia-beliefs, I argue that introspection of qualia is a process that is both epistemically reliable and automatic. It is reliable because it dispenses with justification of any beliefs whatsoever. Moreover, it is automatic because it also dispenses with reflexive connecting beliefs. For example, it takes nonconceptual awareness of the color blue as an input and automatically yields the belief that phenomenal blue is the conscious character of my experience of the sky as an output just by employing the concept BLUE. ${ }^{4}$

This paper is structured in four more sections. The first one is devoted to reconsidering the keystone of the displaced perception model, namely the so-called thesis of transparency of experience, formulated for the first time by Moore, but explicitly endorsed by contemporary authors such as Harman, Dretske, and Tye. ${ }^{5}$ This section is required because it is the claim that experience is transparent that motivates the displaced perception model of knowledge of phenomenal character.

In the second section, I present the displaced model of introspective knowledge of qualia of experience in detail. The third is devoted to presenting the main criticism of Dretske's mold followed by a brief section that appreciates his insufficient replies. Those sections are required because the model that I am proposing here is a rework of Dretske's original displaced perception model. In the penultimate section, I present my deflationary version of the original model to overcome the criticisms. The last one is devoted to defending my view against an objection. Here, is where I argue that even if we assume that we can inwardly perceive qualia in the same way that we perceive particulars, no such de re awareness of the phenomenal character could ever justify the correspondent qualia-belief. That's an argument that traces back to Wittgenstein.

\section{Transparency}

The traditional inner sense model traces back to Locke, but it is endorsed by almost everyone in modern philosophy, such as Hume, Leibniz, and Kant. ${ }^{6}$ The key concept in this tradition is the notion of Reflection, namely the putative ability to turn our minds away from the outside world and towards our own mental states and experiences. In contemporary philosophy of mind, the idea has been taken up again by the so-called high-order theory of consciousness, in particular the so-called higher-order perception theory. ${ }^{7}$ The shared assumption is that we can perceive our own mental states or experiences as some object standing before our minds (Vor-stellen) in the same or a similar way that we can perceive particulars before our conscious mind.

To my knowledge, Moore was the first to call this assumption into question:

And, in general, that which makes the sensation of blue a mental fact seems to escape us: it seems, if I may use a metaphor, to be transparent-we look through it and see nothing but the blue. (1903: p. 446)

That is the so-called transparency thesis of experience. ${ }^{8}$ We are invited to turn our minds away from the world and towards the supposed qualia inherent to sensory experience, say phenomenal blueness. However, when we try to do this, we are told, we fail. All that happens is that we look harder at the color blue itself.

To be sure, transparency is a highly controversial claim. Besides the proponents of the higher-order theories of perception, several authors see no problem with the idea that we are acquainted with mental states and their phenomenal character. According to Balog, for example, what fixes the reference of these phenomenal concepts is a kind of knowledge by acquaintance with the phenomenal character of such mental states. 9 As Balog puts it, a person possesses a phenomenal concept "when he has knowledge by acquaintance of his own conscious states in introspection" (2012: p. 1).

Even avoiding Russell's controversial notion of knowledge by acquaintance, qualia-realistic versions of the so-called "phenomenal concept strategy" suggest that phenomenal concepts are introduced by mental images. Block, for instance, asserts that socalled phenomenal concepts ${ }^{10}$ are shaped by the experience ofin which the empty space is filled by phenomenal properties referred to as concepts. ${ }^{11}$ In a similar vein, Papineau proposes that the structure of experience should be shaped as follows: this experience, in which the demonstrative refers to a type of 
experience exemplified by an image that is associated with the experience in question.

Tye was the one to provide the most precise and interesting account of transparency. According to him, it is due to the impossibility of having such an inner perception of the phenomenal character of experience in the crucial sense that we cannot turn our attentions from the outside world to the phenomenal character of our experience and ask ourselves "what is it (pointing inward to something)?” (Tye, 2014: p. 5). Nevertheless, supporters of the inner sense model still maintain that we can demonstrate inwardly, for example, the phenomenal blue of our experience of the color of the sky in the same way that we can demonstrate the blue color of the sky. ${ }^{12}$

Still, transparency is understood in different ways. Two different meanings are worth noting. The first is the one that Papineau proposed a few years ago. ${ }^{13}$ According to him, when you shift your attention from the sky, turning your mind inwardly into your visual experience, "none of your conscious properties changes; that is, introspection makes no difference to the very conscious nature of its own experience" (2014: p. 22). The idea is that there is no difference to the conscious nature of your visual experience, say, of a blue sky, regardless of whether you are contemplating the blue of the sky, or introspecting on the phenomenal blue of your visual experience of the sky. Nevertheless, it does not follow from this that there is nothing except qualitative properties of outside things to focus on introspectively. The failure to shift focus does not show that we cannot introspect the phenomenal character of experience. It just shows that there's nothing else there to introspect. Let me call this moderate transparency.

The second sense is the one that Tye proposed and the one that all strong representationalists tacitly endorse. This notion traces back to Wittgenstein's idea that a de re perception of a mental state, as well as of its phenomenal character is impossible. Again, you are invited to turn your minds away from the world and towards the supposed qualia inherent to your sensory experience. No matter how hard you try to focus on the phenomenal character of your experience, say phenomenal blue, you are never aware of blue-quale in the relevant sense that you may wonder: "what is that (pointing inside to something)?" (Tye, 2014: p. 5). Thus, no matter how hard you try to focus on the phenomenal blue of your experience, you end up staring at something blue outside of your experiencing mind. Let me call this strong transparency. ${ }^{14}$

I am on Tye's side on the controversy. It seems to me to be counterintuitive to hold that you can stare at the phenomenal blueness of your experience in the same or even a similar way that you stare at a blue surface. Thus, strong transparency is by far the most intuitive claim. Yet, as too much hinges on philosophical intuition, it is pointless to insist that there is no de re awareness of the phenomenal character of experience: "what is it that?" The question is: what is at stake when it seems impossible to pinpoint phenomenal character demonstratively by wondering: "what is that?" My point is purely epistemological. Even if concepts do refer to brain states or to qualia as inherent properties of experience, what strong transparency shows is that no inner perception can ever fix such references and hence justify the normative use of any concepts in introspection. Only through perceptions of outside blue things can we realize what it is like for us to experience blue. Moreover, that is all we need to give up the traditional inner sense model. Let me explain.

The defender of the traditional inner sense model claims to know the phenomenal blue of his experience by acquaintance, based on his inner perception of it. By means of a "flexible demonstrative" he is capable of picking out the phenomenal character: "that is what it is like to experience blue, by pointing to a blue image." ${ }^{15}$ This putative form of knowledge by acquaintance would be exempt from justification, because it is not a propositional form, as we are told. It is based only on an alleged direct relation of contact between the subject and the phenomenal character of the very perceptual state she/he is in. However, everything changes dramatically when we take into account that such knowledge by acquaintance is supposed to justify the employment of the concepts used to pick out the phenomenal character. One thing is to turn our attention inwardly and take a good "look" at the mental image. Is that possible? I do not know! Quite another is to assume that this inward look can determine the reference of the concept BLUE and justify its normative employment in introspection. ${ }^{16}$

In contrast, Dretske and Tye want to force a metaphysical conclusion here. Assuming that a de re perception of phenomenal red is impossible, following the inference to the best explanation (abductive inference), the most plausible conclusion is that the phenomenal character is nothing but the properties that experience represents. ${ }^{17}$ That is the so-called representationalist view on the phenomenal character of experience. Now, assuming representationalism, we must also assume phenomenal externalism: What is the whereabouts of qualia? They are out there.

Is Tye's abductive inference of representationalism (a metaphysical claim about the nature of the phenomenal character of experience) from strong transparency (an epistemological claim) plausible? Maybe it is, maybe it is not. ${ }^{18}$ That is not my concern here. I shall not discuss representationalism except in passing. To some extent this is simply because this paper has a different focus. What I am interested in is the epistemology of qualia, namely how we come to know that phenomenal blueness is the conscious character of my visual experience of the sky, rather than in the nature of phenomenal character. Be that as it may, Dretske and Tye's metaphysical claim obfuscates the epistemological issue of knowledge of qualia.

\section{Displaced perception}

Now, the problems that the inner sense model faces make Dretske's displaced perception model an attractive alternative one. However, what exactly is the displaced perception model in the first place? To start with, perception is "displaced" in the sense that we perceive something via perceiving something else, in Dretske's words: "perceive that $\mathrm{k}$ is $\mathrm{F}$ - by seeing or hearing not directly k, but another particular h" (Dretske, 1995: p. 42). So, displaced perception is required whenever no direct perception of some particular k (object-awareness) is possible or available. Even so, displaced perception is direct rather than indirect because it is assumed that there is a reliable nomic connection between the seen particular " $\mathrm{h}$ " and the fact that $\mathrm{k}$ is $\mathrm{F}$.

Second, displaced perception is always a fact-awareness rather than an object-awareness. The object-awareness of " $h$ " makes me aware of the fact that $k$ is $F$. In other words, displaced perception is always a propositional form of perception, de dicto. Dretske's examples of displaced perception are quite familiar cases of instruments of measure of ordinary life. For example, I secondarily (or displaced) see that there is no gasoline in the tank of my car not by primarily perceiving the gas tank, but by primarily perceiving the position of the gas pointer on the dashboard. Likewise, I displaced perceive the fact that the postman is at my door whenever I hear my dog barking (object-awareness). I secondarily perceive that I have gained twenty pounds by seeing that the scales in my bathroom indicate 20 pounds more. ${ }^{20}$

The analogy with introspection of qualia is quite appealing. Let me recap. As we saw in the last section, I do not see phenomenal blueness as something before the mind. Why is this so? Well, because as Tye has correctly emphasized, there is no possible de 
re or object-awareness of phenomenal blueness as there is of the blue color of the sky, of the Caribbean Sea or of Sinatra's eyes, etc. $^{21}$ Rather, I become aware of the fact (or of the dictum) that phenomenal blueness is the key phenomenal feature of my visual experience (fact-awareness) by seeing the blue color of something that I experience (object-awareness). Therefore, I can only be aware that phenomenal blueness is the key conscious feature of my experience of the sky because I do not have a sensible representation (inner perception) of such phenomenal blue.

Two more key features are crucial. ${ }^{22}$ Indeed, they are the features that raise suspicions about the displaced perception model of introspection as a whole. First of all, as fact-awareness is involved, we need what Dretske calls background connecting beliefs. The idea is that the simple connection between the awareness of some object and the awareness of some fact is not enough for knowledge. The person needs the extra belief connecting the object-awareness to that fact-awareness; an extra belief to the extent that the object-awareness is a reliable sign of the fact-awareness. So, I only know that the postman is at my door because, first, I hear my dogs barking in some particular way and then because I have the extra connecting belief to the effect that I would not be hearing my dogs barking unless the postman was at my door.

Likewise, the simple connection between the awareness of the blue color of the sky and the awareness of the fact that phenomenal blueness is the conscious character of my visual experience of the sky is for Dretske not enough for knowledge of phenomenal character. Introspective knowledge requires an extra belief that appropriately connects the object-awareness to the fact-awareness. I know that phenomenal blueness is the conscious character of my visual experience of the sky because (i) I am aware of the blue color of the sky and because (ii) I have the extra connecting belief that I would not be aware of the blue of the sky unless I was aware of the fact that phenomenal blueness is the conscious feature of my visual experience of the sky. ${ }^{23}$

Finally, in order for connecting beliefs to take place, the subject also needs what Dretske calls a meta-representation, that is, a conceptual representation of a representation as a representation. $^{24}$ The idea is that I could only believe that the postman is at the door because I do represent my dogs are barking as a representation of the postman's presence. Likewise, I can only know that I am experiencing blue because I mentally represent my own representation of something blue as a representation.

\section{The failed analogy}

It is worth noting that in the case of knowledge of the phenomenal character of experience this last claim makes a clear metaphysical commitment: representationalism, namely the claim that the nature of the phenomenal character of experience supervenes on the content of the same experience, that is, on the cluster of properties that that experience represents. Any difference in the representational content, that is, in the properties that experience represents, entails a difference in the phenomenal character of that same experience. That is the reason why I can only know the phenomenal character, e.g., the phenomenal blue of my visual experience of the sky, by conceptually representing what my visual experience represents (the color blue) as a representation.

We are told that the phenomenal character of our experience supervenes on its representational content, that is, on the cluster of properties that our experience represents (representationalism). What it is like for me to feel pain in my toe supervenes on the content of such an experience, roughly on the representation of some damage in my toe. Now, however interesting representationalism might appear to be at first pass, this metaphysical claim is controversial. Without the notion of representation, what remains is the following. I can only know that phenomenal blue is the conscious character of my visual experience of the sky because, first, I am aware of the blue color of the sky via my experience and, second, because I have the extra connecting belief that I would not be aware of the blue of the sky unless I was aware of the fact that phenomenal blueness is the conscious feature of my visual experience of the sky.

Yet, the main problem of the displaced model of introspection is the very notion of connecting beliefs. The first question that the displaced model raises is whether those connecting beliefs would not render introspection of the phenomenal character indirect rather than direct. ${ }^{25}$ Indeed, the analogies employed strongly suggest that we are facing a classic case of empirical induction. For example, I know that the postman is at the door by hearing my dogs barking in a particular way (likewise, I know that the fuel tank of my car is empty by seeing the fuel gauge on the car's dashboard, etc.). The question is: how is my knowledge-claim justified?

Well, it is simple as this. I advert to my past experiences: whenever I have heard the dogs barking in that particular way the postman has been at my door. Projecting the past into the future, I am entitled to believe that the postman is at my door whenever I hear my dogs barking. Yet, if introspection of the phenomenal character is indirect rather direct, how could it be justified since there is no past experience involved? What past experiences could entitle my belief that phenomenal blue is the conscious character of my visual experience of the sky? If I advert to my perceptual experience of the sky, I fall prey of a vicious circle: the phenomenal blueness of my visual experience of the sky and my experience of the sky are one and the same experience. Obviously, to advert to some higher-order experience is out of the question. For one thing, to appeal to a second-order experience of the phenomenal blueness of my visual experience is to fall back into the inner sense model of introspection that the displaced model aims to replace. For another, this appeal launches an infinite regress since no inner perception could fix the reference of a concept to the phenomenal character of experience.

Moreover, even if we could advert to some past experiences in order to justify the connecting beliefs, by all accounts, I know that phenomenal blueness is the conscious character of my experience of the sky directly and a priori, that is, quite independently of any observation whatsoever. Intuitively, whenever I feel pain in my toe I do not inspect my toe to observe whether it is injured to justify the claim that I know that I am in pain. Obviously, Dretske was quite aware of that trivial fact. Indeed, nobody denies that I know directly and a priori that phenomenal blueness is the conscious character of my visual experience of the sky. How can the displaced model of introspection of the phenomenal character of experience do justice to such strong intuition if the model relies on connecting beliefs?

\section{Unsatisfactory replies}

Dretske anticipates these objections and presents two replies. First, he argues that the truth of the conclusion in any inference (inductive or not) always depends on the truth of its premises. However, in the displaced perception model we would always have a true conclusion (I am aware that phenomenal blue is the fundamental feature of my experience), even when the supposed premise was wrong (for example, I was hallucinating a blue sky). To this he adds that induction is always fallible. According to Dretske, however, the putative conclusion of the supposed inductive inference (I am aware of the phenomenal blue of my experience of the sky) is infallible. He concludes that the application of the displaced perception model to introspection does not result in a classic case of induction: no past experience is needed. ${ }^{26}$ 
Both of these distinctions seem to be correct. Yet, it seems that in making them, Dretske appears to be rejecting his very attempt at explaining introspective knowledge of qualia as a displaced perception. For one, he argues that one can garner knowledge about a certain thing $y$ not from perceiving that thing but from perceiving a different thing $\mathrm{x}$. Yet, if one is to assume that there is no inference from the perception of one thing to knowledge about another, there seems to be no displaced perception after all. What is wanting is not the idea that one can garner knowledge about one object by perceiving another, but an explanation of how this occurs in the first place.

The key problem is: how are connecting beliefs epistemically justified? To be sure, if displaced perception were an inductive inference, the conclusion could not be true if both premises were not so in the first place. Moreover, whenever I feel pain, I cannot be mistaken. So, let us suppose, for the sake of argument, that we in fact are not facing a case of inductive inference. Now, it is still hard to understand how one could justify the connecting beliefs precisely because they are not based on induction and hence on past experiences. Again, I can justify the ordinary belief that the postman is at the door after hearing my dogs barking in a particular way because I have the extra connecting belief that my dogs would not be barking unless the postman was at my door. Still, what would allow me to justify the connecting belief that I would not be aware of the color blue of the sky unless I was aware of the fact that phenomenal blue is the conscious character of my visual experience of the sky?

\section{A simpler account}

Let me recap. Representationalism invites two questions. First, must we really assume that the nature of phenomenal character supervenes on the content of experience to make sense of introspection of qualia as a displaced perception? Second, even assuming that introspecting qualia involves concepts, why must those concepts take the form of a meta-representation (a representation of a representation as a representation) $?^{27}$ In this regard, my proposal is simply to rule out all metaphysical claims about the nature of qualia that unnecessarily burden the displaced perception model of introspection of the phenomenal character of experience.

Given this, we do not need the concept of representation let alone the concept of meta-representation (representation of a representation as a representation). That implies a highly controversial metaphysical claim that must be avoided in any reasonable discussion of the epistemology of qualia. Instead, with the failure of the inner sense model, all we need is to assume, following Wittgenstein, that any reference to the phenomenal character of experience is determined by something else outside the experiencing mind. In this way, we leave open what the nature of phenomenal character is: it can be either what experience is supposed to represent (representationalism) or something that takes place inside our brains (qualia realism) or whatever you want. We only assume that qualia exist (against qualia-eliminativists).

The requirement of connecting beliefs invites additional insurmountable problems. First, it suggests that introspection in the displaced perception model relies on empirical induction, which contradicts the strong intuition that introspective knowledge of phenomenal character is direct and a priori. Second, assuming that connecting beliefs are not empirical inductions, I see no way how they could be justified. Moreover, they are not really required for introspecting qualia in the first place. $^{28}$

What I retain from the original insight are three capital tenets. The first is the rejection of the traditional inner sense model. However, as I have argued, my concern here is not whether we can really be acquainted with qualia as the inner sense model assumes. Secondly, I endorse the claim that knowledge of the phenomenal character of experience is always knowledge of a fact. Finally, I also endorse the "displaced" claim that introspecting the phenomenal character of experience is becoming aware of the phenomenal character via perceiving something else outside the experiencing mind. However, I have to admit the idea of a "displaced perception" is misleading to say the least. Knowing qualia via knowing a fact is not to perceive qualia in a displaced way.

The question now is: if connecting beliefs are unnecessary, what could replace them in the original model? Let us take a closer look at the original model. Again, I can only know that the postman is at my door, by hearing my dogs barking in a particular way, because I additionally believe that my dogs would not be barking in that way unless the postman was at the door. In other words, I can only know that the postman is at my door by hearing my dogs barking in a particular way because I believe that the dogs barking is a reliable sign of the fact that the postman is at my door. Likewise, I can only know that phenomenal blue is the conscious character of my experience of the sky by being aware of the color blue of the sky because I believe that I would not be aware of the fact that phenomenal blue is the conscious character of my experience of the sky unless I was aware of the color blue of the sky. In other words, I can only know that phenomenal blue is the conscious character of my experience of the sky by perceiving the color blue of the sky because I believe that the awareness of the blue of the sky is a reliable sign of the fact that I am experiencing blue.

Now, if we leave aside the connecting belief, what remains is just the nomic causal relation between the object-awareness and the fact-awareness: the awareness of the blue of the sky is a reliable sign of the fact that phenomenal blue is the conscious character of my visual experience of the sky. Nothing more, nothing less is required. I am entitled to believe that phenomenal blueness is the conscious character of my experience of the sky just because I am aware of the color blue of the sky. I do not need some extra connecting belief to the effect that I am consciously aware that the awareness of the blue color of the sky is a reliable sign of the awareness of the fact phenomenal blueness is the conscious character of my experience of the sky.

So, knowledge of phenomenal character is a reliable and automatic process. It is reliable because it dispenses with reflexive connecting beliefs, relying entirely on subliminal nomic causal relations between object- and fact-awareness. However, it is also automatic insofar as it takes the nonconceptual awareness of the color blue as an input and automatically yields the belief that phenomenal blue is the conscious character of my experience of the sky just by employing the concept BLUE as an output.

\section{Objection}

Now, someone could insist that by giving up connecting beliefs I am giving up the claim of providing an explanation for knowledge of qualia without assuming the inner sense model. If, in the case of introspective knowledge, one is to assume that there is no connecting belief from the perception of one thing to knowledge about another, it seems that one must conclude that introspective knowledge is not a form of displaced perception after all. To be sure, in usual cases of induction, one can garner knowledge about a certain fact (e.g., the fact that the postman is at my door) not from perceiving that fact itself, but from perceiving something else (my dogs barking). Why is this so? Well, I have the extra connecting belief that I would not be hearing my dogs barking unless I was aware of the fact that the postman was at my door. This is what Dretske terms displaced perception. Thus, I must believe that I am aware of the fact that the postman is at my door because I also believe that my hearing the dogs barking is a reliable sign of the fact that the postman is at my door. 
However, as I have claimed, no connecting beliefs are involved. Therefore, there seems to be no displaced perception involved. This raises the suspicion that I believe that the blue-quale is the conscious character of my experience of the sky not because I am aware of the color blue of the sky, but rather because I perceive inwardly the blue-qualia of my experience of the sky. Here, someone sympathetic to Papineau's moderate transparency could still hold that the unperceived shift from the inside to the outside world does not eliminate the fact that we do in fact perceive inwardly the phenomenal character of experience of the sky.

It is here that I believe the central lesson of Wittgenstein's socalled Private Language Argument can provide us with some light. Let us assume that I see inwardly the mental image of blue (phenomenal blue) and every time that I want to justify my use of the concept BLUE to pick phenomenal blue out, I advert to that image. However, how can I know that I have the true image of red whenever I think of phenomenal blue? Here Wittgenstein's lesson comes in: "But what is this ceremony for?” (2009: PI \$258). To appeal to higher-order states in order to justify the supposition that, on both occasions, we are de re perceiving the same phenomenal blue is just like buying a second copy of the same newspaper to make sure that what the first copy says is true. We launch an infinite or vicious regress, and there is only one way to stop it: to turn our attention away from our experiencing mind to the outside world our experience is about. I believe that this is a noncontroversial claim that we can extract from strong transparency.

Epistemologically, the most that we can reasonably extract from the strong transparency claim is the forgotten lesson of Wittgenstein's Private Language Argument. Whatever concepts refer to, any putative inner perception of phenomenal character could never determine the reference and justify the normative employment of concepts in introspection to pick out the phenomenal character of experience. Given this, the abandonment of connecting belief does not force us back to the inner sense model.

Received: 3 February 2020; Accepted: 18 May 2020;

Published online: 17 June 2020

\section{Notes}

1 Lycan, after Armstrong, updates the internal perception model, replacing the original metaphor of an "inner eye" with the metaphor of internal monitoring.

2 See Dretske, 1995.

3 Indeed, we do not need to assume even the so-called "content view" of perception, namely the widespread assumption that perception has veridicality conditions. For example, when I see a moth on a tree, I represent the world as being a certain way; that is, my perceptual states have veridicality conditions. The direction of fit is mindto-world, or content-to-world. When there is a match between the way that our perceptual experiences represent the world as being and the way the world is, their representational content is veridical; otherwise the content is nonveridical. Thus, when I see a moth on a tree, the content of my perception is veridical iff there is a moth where I am looking, but nonveridical iff there is nothing or there is something else. "Content view" is Campbell's label. See Campbell, 2002.

4 Actually, it is irrelevant for my claim whether there are phenomenal concepts in the relevant sense of concepts that could only be acquired via the relevant experience. In this regard, see Tye's (2009) criticisms. Instead of a phenomenal concept BLUENESS, the subject might reuse his ordinary concept RED for the recognition of both the nonconceptual content of the experience of red, as well as its phenomenal redness. What is relevant for my position is the view that (i) no inner perception can fix the reference and justify the employment of the concept involved, and (ii) regardless of whether I am using the ordinary concept BLUE, I am not committed to the metaphysical claim that phenomenal redness is just the red that experience represents.

5 The transparency claim is the one that authors like Moore, Wittgenstein, and more recently Harman, Dretske, and Tye share. See Moore, 1903; Harman, 1990; Dretske, 1995; Papineau, 2014; Tye, 1995, 2000, 2002; 2009, 2014.

6 John Locke, for example, said that "... [c]onsciousness is the perception of what passes in a man's own mind" (1690/1975, bk. 2, ch. 1, p. 115).
7 The literature is huge. See Carruthers, 1989, 1996, 1999, 2000, 2005, 2016; Gennaro 1996, 2004a, 2004b, 2005, 2012; Lycan, 1987, 1996, 2001a, 2001b, 2004; Rosenthal, 1986, 1993, 2004, 2005, 2011.

8 See also Wittgenstein, 2009.

9 See Balog, 2012.

10 "Phenomenal concepts" are special concepts that pick out the phenomenal character of experience in introspection but that could only be acquired when the subject undergoes the relevant experience. Phenomenal concepts are the main tools in the strategy to defend physicalism against Jackson's knowledge argument, the so-called "phenomenal concept strategy." See Stoljar, 2005. The idea is that, on her release from the back-and-white room, Mary acquires new special phenomenal concepts of some physical property or fact she already recognized as a physical concept in her confinement. Ball (2009) and Tye (2009) have persuasively argued against the existence of such concepts in the special sense. However, in this paper I suspend my judgment in this respect. All that I need to assume here is the existence of concepts used to pick out qualia introspectively. The literature about the "phenomenal concept strategy" is huge. See Alter, 2013; Carruthers, 2004; Chalmers, 2010; Crane, 2012; Horgan, 1984; Ismael, 1999; Jackson, 1982; Levine, 1983; 2006b; Loar, 1990/97; Nemirow, 2006; Nida-Rümelin, 1996, 2002; O’Dea, 2002; Papineau, 2006; Perry, 2001; Stoljar, 2005; Tye, 2000, 2003, 2009, 2012.

11 See Block, 2006: p. 48, n. 31.

12 Yet, by far the most bizarre form of resurgence of the notion of acquaintance is certainly the one that Perry (2001) recently proposed. He conceives phenomenal concepts as "flexible" and "internal" demonstratives, as if we could literally look inward and indicate the phenomenal character of our experience as "this" in the same way that we use ordinary statements to indicate objects in space. See Perry, 2001: p. 146.

13 See Papineau, 2014.

14 Strong transparency was defended by Dretske, 1995; Evans, 1982; Martin, 2002; Shoemaker, 1994; Stoljar, 2004; Tye, 1995, 2000, 2002; Van Gulick, 1993. The opposite view is hold by Goldman, 2006; Petitmengin, 2006; Hill, 2009; Siewert, 2012. 15 See Perry, 2001.

16 I will come back to this in the last section.

17 See Tye, 2014.

18 By far the most striking argument against phenomenal externalism is Block's inverted earth scenario.

19 Seager $(2000)$ and Tye $(1995,2000)$ explicitly endorse versions of this account. Shoemaker's view of introspection (1996) can also be seen as a variation of this line.

20 See Dretske, 1995, Chapter 2. This opposition traces back to Dretske's opposition between "non-epistemic seeing" and "epistemic seeing." See Dretske, 1969. The same opposition reappears in Dretske, 1999. Fact-awareness is what he later called "epistemic seeing," that is, a perceptual propositional attitude: I see that something is the case. In contrast, "object-awareness" is what he later called "non-epistemic seeing," that is, a perception of things rather than facts.

21 Tye, 2014

22 As we are going to appreciate in the next section, they are troublesome.

23 I am phrasing the connecting belief in terms of this counterfactual because it is a causal belief covered by law-like connections.

24 See 1995, p. 43.

25 That is the first of Lycan's charges. See Lycan, 1996.

26 Lycan was the first to raise this objection. See Lycan, 1987, 1996. In regard of the debate.

27 Indeed, the model is associated with a second metaphysical claim. The idea here is that bodily sensations, emotions, humors, and proprioception also have representational contents with veridicality conditions. For example, when I feel pain in my toe, I do represent, roughly, that my toe is damaged. That content is veridical when in fact my toe is somehow damaged; otherwise it is nonveridical. See Dretske, 1995 and Tye, 1995.

28 Given this, we do not need any putative background knowledge or experience. This knowledge is required when we are urged to justify the belief that our gas tank is empty by means of the perception of the position of the pointer on the car's dashboard. By assuming a reliable account of self-knowledge, no justification is required. The person sees something red and that is all that it is required for her to be entitled to believe that phenomenal redness is the conscious character of her visual experience. The only need is to master the relevant concept BLUE, nothing else.

\section{References}

Alter T (2013) Social externalism and the knowledge argument. Mind 122:481-496 Balog K (2012) Acquaintance and the mind-body problem. In: Simone Gozzano \& Christopher S. Hill (eds.), New perspectives on type identity: the mental and the physical. Cambridge University Press, pp. 16

Block N (2006) Max Black's objection to mind-body identity. Oxf Rev Metaphysics 3:3-78

Campbell J (2002) Reference and consciousness. Oxford University Press, Oxford Carruthers P (1989) Brute experience. J Philos 86:258-269 
Carruthers P (1996) Language, thought and consciousness. Cambridge University Press, Cambridge

Carruthers P (1999) Sympathy and subjectivity. Australas J Philos 77:465-482

Carruthers P (2000) Phenomenal consciousness: a naturalistic theory. Cambridge University Press, Cambridge

Carruthers P (2004) Phenomenal concepts and higher-order experiences. Philos Phenomenological Res 68:316-36

Carruthers P (2005) Consciousness: essays from a higher-order perspective. Oxford University Press, Oxford

Carruthers P (2016) "Higher-order theories of consciousness." In: Edward N. Zalta (ed.). The Stanford Encyclopedia of Philosophy (Fall 2016 edn). https://plato. stanford.edu/archives/fall2016/entries/consciousness-higher/

Chalmers DJ (2010) The character of consciousness. Oxford University Press

Crane T (2012) Tye on acquaintance and the problem of consciousness. Philos Phenomenological Res 84(1):190-98

Dretske F (1969) Seeing and knowing. Philos Q 21(82):82-83

Dretske F (1995) Naturalizing the mind. MIT Press

Dretske F (1999) The mind's awareness of itself. Philos Stud 95(1):103-124

Evans G (1982) The varieties of reference. J McDowell (ed.), Oxford University Press, Oxford: Clarendon; New York

Gennaro R (1996) Consciousness and self-consciousness. John Benjamins, Amsterdam

Gennaro R (2004a) Higher-order theories of consciousness. John Benjamins, Philadelphia

Gennaro R (2004b) Higher-order thoughts, animal consciousness, and misrepresentation: A Reply to Carruthers and Levine. In: R. Gennaro (ed.), 45-66

Gennaro R (2005) The HOT theory of consciousness: between a rock and a hard place. J Conscious Stud 12:3-21

Gennaro R (2012) The consciousness paradox: Consciousness, concepts, and higher-order thoughts. MIT press, Cambridge, MA

Goldman AI (2006) Simulating minds. Oxford, Oxford

Harman G (1990) The intrinsic quality of experience. Philos Perspect 4:31-52

Hill CS (2009) Consciousness. Cambridge University Press, Cambridge

Horgan T (1984) Jackson on physical information and qualia. Philos Q 34:147-183

Ismael J (1999) Science and the phenomenal. Philos Sci 66:351-369

Jackson F (1982) Epiphenomenal qualia. Philos Q 32(April):127-136

Levine J (1983) Materialism and qualia: the explanatory gap. Pac Philos Q 64 (October):354-361

Levine J (2006b) What is a phenomenal concept? In: Alter T, Walter S (eds) Phenomenal concepts and phenomenal knowledge: new essays on consciousness and physicalism. Oxford University Press, Oxford

Loar B (1990/97). Phenomenal states. In: J. Tomberlin (ed) Philosophical perspectives 4: action theory and philosophy of mind. Ridgeview, Atascadero, CA, USA, pp. 81-108 (revised version in "The nature of consciousness (1997)", In: Block N, Flanagan O, Güzeldere G (eds). MIT Press, Cambridge, pp. 597-616)

Locke J (1690/1795) An essay concerning human understanding. Basset, London (my page reference is to the Nidditch edition, Oxford: Oxford University Press, Oxford)

Lycan WG (1987) Consciousness. MIT Press, Cambridge, MA

Lycan WG (1996) Consciousness and experience. MIT Press, Cambridge, MA

Lycan WG (2001a) "Have we neglected phenomenal consciousness?". Psyche 7. Available from the ASSC depository

Lycan WG (2001b) A simple argument for a higher-order representation theory of consciousness. Analysis 61:3-4

Lycan WG (2004) The superiority of HOP to HOT. In: R. Gennaro (ed.), 93-114

Martin MGF (2002) The transparency of experience. Mind Lang 17:376-425

Moore GE (1903/1993). Selected writings. Routledge

Nemirow L (2006) So this is what it's like: a defense of the ability hypothesis. In: Alter $\mathrm{T}$, Walter S (eds). Phenomenal concepts and phenomenal knowledge: new essays on consciousness and physicalism. Oxford University Press, Oxford

Nida-Rümelin M (1996) What Mary couldn’t know. In: Metzinger T (ed). Conscious perience. Imprint Academic, Exeter, pp 219-241

Nida-Rumelin M (2002) Qualia: the knowledge argument. In: Zalta E (ed) Stanford Encyclopedia of Philosophy. http://plato.stanford.edu

O'Dea J (2002) The indexical nature of sensory concepts. Philos Pap 31:169-181

Papineau D (2006) Phenomenal concepts and the materialist constraint. In: Alter T, Walter S (eds). Phenomenal concepts and phenomenal knowledge: new essays on consciousness and physicalism. Oxford University Press, Oxford

Papineau D (2014) The presidential address: sensory experience and representational properties. Proc Aristotelian Soc 114(1pt1):1-33

Perry J (2001) Knowledge, possibility, and consciousness. MIT Press
Petitmengin C (2006) Describing one's subjective experience in the second person: an interview method for the science of consciousness. Phenomenol Cogn Sci 5:229-269

Rosenthal D (1986) Two concepts of consciousness. Philos Stud 49:329-359

Rosenthal D (1993) Thinking that one thinks. In M. Davies \& G. W. Humphreys (eds), Readings in mind and language, Consciousness: Psychological andphilosophical essays vol. 2. Blackwell Publishing, p 197-223

Rosenthal D (2004) Varieties of higher-order theory. In: Gennaro R (ed), 17-44

Rosenthal D (2005) Consciousness and mind. Oxford University Press, Oxford

Rosenthal D (2011) Exaggerated reports: reply to Block. Analysis 71:431-437

Seager W (2000) Introspection and the elementary acts of mind. Dialogue 39 (1):53-76

Shoemaker S (1994) Self-knowledge and 'inner sense'. Lecture I: the object perception model. Philos Phenomenological Res 54:249-269

Shoemaker S (1996) The First Person Perspective and Other Essays. Cambridge University Press

Siewert C (2012) On the phenomenology of introspection. In: Smithies Declan, Stoljar Daniel (eds), Introspection and consciousness. Oxford, Oxford

Stoljar D (2004) The argument from diaphanousness. In: Ezcurdia M, Stainton RJ, Viger C (eds.) New essays in the philosophy of language and mind. University of Calgary, Calgary, pp. 341-390

Stoljar D (2005) Physicalism and phenomenal concepts. Mind Lang 20:469-494

Tye M (1995) Ten problems of consciousness: a representational theory of the phenomenal mind. MIT Press

Tye M (2000) Consciousness, color, and content. MIT Press, Cambridge, MA

Tye M (2002) Representationalism and the transparency of experience. Noûs 36:137-151

Tye M (2003) A theory of phenomenal concepts. In: Anthony O'Hear (ed) Royal Institute of Philosophy Supplement. Cambridge University Press, Cambridge pp. 91-105

Tye M (2009) Consciousness revisited: materialism without phenomenal concepts. MIT Press

Tye M (2012) Reply to Crane, Jackson and McLaughlin. Philos Phenomenological Res 84(1):215-232

Tye M (2014) Transparency, qualia realism and representationalism. Philos Stud 170(1):39-57

Van Gulick R (1993) Understanding the phenomenal mind: are we all just armadillos? In: Davies M, Humphreys GW (eds.) Consciousness: psychological and philosophical essays. Blackwell, Oxford, pp. 134-154

Wittgenstein L (2009) Philosophical investigations, 4th edn (trans. Hacker and Schulte). Wiley-Blackwell

\section{Competing interests}

The author declares no competing interests.

\section{Additional information}

Correspondence and requests for materials should be addressed to R.H.d.S.P.

Reprints and permission information is available at http://www.nature.com/reprints

Publisher's note Springer Nature remains neutral with regard to jurisdictional claims in published maps and institutional affiliations.

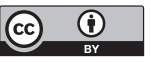

Open Access This article is licensed under a Creative Commons Attribution 4.0 International License, which permits use, sharing, adaptation, distribution and reproduction in any medium or format, as long as you give appropriate credit to the original author(s) and the source, provide a link to the Creative Commons license, and indicate if changes were made. The images or other third party material in this article are included in the article's Creative Commons license, unless indicated otherwise in a credit line to the material. If material is not included in the article's Creative Commons license and your intended use is not permitted by statutory regulation or exceeds the permitted use, you will need to obtain permission directly from the copyright holder. To view a copy of this license, visit http://creativecommons.org/ licenses/by/4.0/.

(C) The Author(s) 2020 